\title{
Ação alelopática de óleos essenciais de alecrim-pimenta e capim- santo na germinação de aquênios de alface
}

\section{Allelopathic action essential oils of alecrim-pimenta and lemongrass in germination of lettuce achenes}

\author{
Hélida Mara Magalhães ${ }^{1 *}$; César Fernandes Aquino ${ }^{2}$; Eriksen Patric Silva Soares ${ }^{3}$; \\ Leonardo David Tuffi Santos ${ }^{4}$; Paulo Sergio Nascimento Lopes ${ }^{4}$
}

\section{Resumo}

O alecrim-pimenta e o capim-santo produzem compostos secundários que podem ser utilizados no manejo alternativo de plantas daninhas. Objetivou-se com esse trabalho verificar o efeito alelopático dos óleos essenciais de alecrim-pimenta e capim-santo na geminação de aquênios de alface. Foram utilizadas folhas maduras de ambas as espécies, e extraído o óleo essencial pelo método de destilação de arraste por vapor de água. O bioensaio foi realizado utilizando aquênios de alface da cultivar crespa de verão e arranjado em esquema fatorial $5 \times 2$ sendo cinco concentrações $0,0,25,0,5,0,75$ e $1,0 \%$ e duas espécies de plantas medicinais. Foram utilizadas 4 repetições com 50 aquênios. O óleo de capimsanto foi prejudicial à germinação de aquênios de alface, sendo esse efeito dependente da concentração. Houve redução de $34 \%, 12 \%$ e $75 \%$ da germinação de aquênios de alface tratados com o óleo de capim-santo nas concentrações de $0,25 \%, 0,75 \%$ e $1,0 \%$ respectivamente comparando-se ao óleo de alecrim-pimenta. O índice de velocidade de germinação, o comprimento e a massa seca do hipocótilo e da radícula das plântulas de alface, foram comprometidos pelo contato dos óleos de alecrim-pimenta e capim-santo com os aquênios do bioindicador. Embora tenha ocorrido à germinação dos aquênios de alface tratados com óleo de alecrim-pimenta a porcentagem de plântulas anormais foi elevada, o que compromete sua sobrevivência.

Palavras-chave: Cymbopogon citratus, Lippia sidoides, aleloquímico, bioherbicida

\begin{abstract}
The alecrim-pimenta and the lemongrass produce secondary compounds that can be used in alternative management of weed. The objective of this work was to evaluate the allelopathic effect of the essential oils of alecrim-pimenta and lemongrass in germination of lettuce achenes. It was used mature leaves of both species, and extracted the essential oil by distillation method of drag by water vapor. The bioessay was performed using achenes of crisp-leaf lettuce for summer and arranged in factorial scheme $5 \times 2$, being five concentrations of $0,0.25,0.5,0.75$ and $1.0 \%$ and two species of medicinal plants. It was used four replicates of 50 achenes. The oil of lemongrass was more detrimental to the germination of lettuce achenes when compared with the oil of alecrim-pimenta, being this effect dependent of the concentration. Germination of lettuce achenes treated with lemongrass oil declined by $34 \%, 12 \%$ and
\end{abstract}

${ }^{1}$ Eng $^{\text {o }}$ Agr $^{\circ}$, Doutoranda em Fitotecnia, Universidade Federal de Lavras, UFLA, Lavras, MG. E-mail: helidamara@hotmail.com

${ }^{2}$ Eng $^{\circ}$ Agr $^{\circ}$, Doutorando em Fitotecnia, Universidade Federal de Viçosa, UFV, Viçosa, MG. E-mail: cesarfernandesaquino@, yahoo.com.br

${ }^{3}$ Eng $^{\mathrm{o}} \mathrm{Agr}^{\mathrm{o}}$, Mestrando em Produção Vegetal, Universidade Estadual de Montes Claros, UNIMONTES, Janaúba, MG. E-mail: eriksenpatric@yahoo.com.br

${ }^{4}$ Eng $^{{ }^{\text {s }}}$ Agr $^{\text {os }}$, Profs. da Universidade Federal de Minas Gerais, UFMG, Montes Claros, MG. E-mail: 1tuffi@ica.ufmg.br; psnlopes@ ica.ufmg.br

* Autor para correspondência 
$75 \%$ for concentrations of $0.25 \%, 0.75 \%$ and $1.0 \%$, respectively when compared with alecrim-pimenta oil. The germination speed index, the length and dry weight of hypocotyl and radicle of lettuce seedlings was compromised by the contact of alecrim-pimenta and lemongrass oils. Although there were lettuce achenes germination treated with alecrim-pimenta oil, the percentage of abnormal seedlings was high, which compromises their survival.

Key words: Cymbopogon citratus, Lippia sidoides, allelochemical, bioherbicid

\section{Introdução}

Nos últimos anos a conscientização da sociedade sobre a degradação ambiental, e a necessidade por alimentos livres de agrotóxicos tem crescido levando a busca por meios alternativos de controle de plantas daninhas e de microrganismos com o objetivo de preservar os recursos naturais, e a qualidade dos alimentos utilizados na dieta do homem e animais. Dessa forma, a atividade de biomoléculas presente em vegetais, tem sido usada como alternativa ao uso de herbicidas, fungicidas, inseticidas e nematicidas (SODAEIZADEH; RAFIEIOLHOSSAIN; VANDAMM, 2010; FAROOQ et al., 2011). Nesse contexto as espécies medicinais têm recebido atenção especial, pelos diferentes significados que elas assumem na sociedade como recurso biológico e cultural, com destaque para seu potencial na produção de compostos, para o uso na indústria, medicina e agricultura.

Os vegetais liberam no ambiente, diversos metabólitos que podem influenciar de forma positiva ou negativa o crescimento e desenvolvimento da vegetação adjacente, fenômeno conhecido como alelopatia (FAROOQ et al., 2011). A capacidade de influenciar negativamente o desenvolvimento de plantas confere as substâncias produzidas por elas, bem como de outros organismos, a definição de herbicidas naturais ou bioherbicidas.

A resistência ou tolerância a esses metabólitos é específica, existindo espécies menos ou mais sensíveis que outras. A alface (Lactuca sativa) e o tomate (Lycopersicum esculentum) são reconhecidamente sensíveis à ação desses compostos, o que aliado a uniformidade durante os processos de germinação de suas sementes, confere a essas espécies boas características para avaliação de bioensaios com alelopatia (FERREIRA; ÁQUILA, 2000).

O efeito alelopático de óleos essenciais e de extratos de plantas já foi comprovado em alguns estudos e indicam as potencialidades do uso dos metabólitos secundários presentes nas diversas espécies vegetais (ALVES et al., 2004; DAIZY et al., 2004; DE FEO; SIMONE; SENATORE, 2002; MAGIERO et al., 2009; ROSADO et al., 2009; SALAMCI et al., 2007). O capim-santo (Cymbopogon citratus (DC.) Stapf.) e o alecrimpimenta (Lippia sidoides Cham.) são espécies medicinais, com reconhecida capacidade de produção de compostos secundários (ALVES et al., 2004; MARTINS et al., 2002) e com possibilidades de uso como bioherbicida.

Desta forma, o objetivou-se com esse trabalho, avaliar o efeito inibidor dos óleos essenciais de alecrim-pimenta e capim-santo sobre a geminação de aquênios de alface.

\section{Material e Métodos}

O experimento foi conduzido no Laboratório de Óleos e Biotecnologia, do Instituto de Ciências Agrárias da Universidade Federal de Minas Gerais, campus Montes Claros. O material vegetal para a obtenção dos óleos essenciais foi obtido no horto de plantas medicinais do mesmo instituto.

Nas primeiras horas da manhã foram coletados $5,0 \mathrm{Kg}$ de folhas maduras de forma aleatória em toda extensão das plantas de alecrim-pimenta e capim-santo, em quatro indivíduos por espécie, e acondicionadas separadamente em sacolas plásticas. 
Após a colheita, seguiu-se imediatamente para extração dos óleos, sem previa lavagem das folhas. Para a extração, empregou-se o método de destilação de arraste por vapor de água, utilizando o destilador piloto Linax, modelo D20. O tempo para o processo completo de extração foi de 3 horas ininterruptas para cada material vegetal. Ao final do processo o óleo foi separado do hidrolato por partição líquidolíquido, sendo os óleos armazenados em frascos tipo âmbar, e conservados por três dias em freezer a temperatura e umidade não controladas (MARTINS et al., 2002).

Ao implementar o experimento os óleos foram emulsionados com espalhante adesivo (Tween $80^{\circledR}$ ), na concentração de $1 \%(\mathrm{v} / \mathrm{v})$ para facilitar a imersão em água. A partir da solução emulsionada foram obtidas soluções aquosas nas concentrações a serem testadas. Utilizou-se o delineamento inteiramente casualizado (DIC), em esquema fatorial $5 \times 2$, sendo cinco concentrações $(0,0 \%, 0,25 \%, 0,50 \%, 0,75 \%$ e 1,0\%) x 2 óleos essenciais de alecrim-pimenta (Lippia sidoides) e capim-santo (Cymbopogon citratus) com 4 repetições de 50 aquênios de alface da cultivar crespa de verão. Como tratamento controle usou-se apenas a solução de espalhante adesivo Tween $80^{\circledR} 1 \%(\mathrm{v} / \mathrm{v})$, sem nenhuma adição dos óleos essenciais.

O bioensaio foi realizado segundo metodologia prescrita pelas Regras de Análise de Sementes (BRASIL, 2009). Em caixas tipo gerbox de $11 \mathrm{x}$ 11 x $3 \mathrm{~cm}$ forradas com duas folhas de papel de filtro, e umedecidas com volume de água destilada equivalente a 2,5 vezes a massa do papel seco, adicionaram-se $4 \mathrm{~mL}$ dos respectivos tratamentos. Em seguida os aquênios de alface foram semeados. As caixas gerbox foram transferidas para câmara de germinação tipo BOD regulada para temperatura de $25{ }^{\circ} \mathrm{C}$ constante e na ausência de luz. Quando necessário, as folhas de papel de filtro foram mantidas úmidas com adição de $6 \mathrm{~mL}$ água destilada autoclavada para cada caixa gerbox.
As contagens de germinação de aquênios foram realizadas diariamente até o sétimo dia após a semeadura. Considerou-se germinado os aquênios com a presença da protrusão da radícula em 0,1 $\mathrm{mm}$. Decorridos os sete dias, foram avaliados as seguintes características: germinação, índice de velocidade de germinação (IVG) de acordo com Maguire (1962); comprimento das raízes primárias e do hipocótilo, avaliado com auxílio de régua milimetrada; massa seca da raiz e do hipocótilo, obtidos com o uso de estufa de circulação forçada ajustada a temperatura de $65^{\circ} \mathrm{C}$ até massa constante. Além disso, foi realizada avaliação visual sobre o estado das plântulas, sendo observado: necrose na raiz, presença de raízes laterais, plântula anormal e movimento gravitrópico alterado. As plantas foram consideradas normais ou anormais seguindo as Regras para Análise de Sementes (BRASIL, 2009).

Os dados foram submetidos à análise de variância e, posteriormente, quando qualitativos, as médias comparadas pelo teste de Tukey $(p<0,01)$ e quando quantitativos por regressão polinomial $(p<0,01)$, conforme Banzatto e Kronka (2006).

\section{Resultados e Discussão}

O óleo essencial de capim-santo diminuiu $(\mathrm{p}<0,01)$ à percentagem e o índice velocidade de germinação dos aquênios de alface quando comparado com o óleo essencial de alecrimpimenta, exceto nas concentrações de 0 e $0,75 \%$ onde não observou-se diferença significativa (Tabela 1). A curva de regressão ajustada para a porcentagem de germinação assumiu modelo linear decrescente à medida que as concentrações dos óleos foram elevadas, independente da espécie (Figura 1). De maneira semelhante à germinação, o índice de velocidade diminuiu com aumento das concentrações dos óleos essenciais (Figura 2), porém, com taxa de redução mais acentuada quando utilizado o óleo de capim-santo. 
Tabela 1. Médias da percentagem de germinação, do índice de velocidade de germinação (IVG), do comprimento do hipocótilo e da radícula e percentagem de plântulas anormais de aquênios de alface, submetidos às concentrações crescentes dos óleos essenciais de alecrim-pimenta e capim-santo.

\begin{tabular}{|c|c|c|c|c|c|}
\hline \multicolumn{6}{|c|}{ CONCENTRAÇÃO (\%) } \\
\hline \multirow{2}{*}{ ÓLEOS } & \multicolumn{5}{|c|}{$\%$ de Germinação } \\
\hline & 0 & 0,25 & 0,50 & 0,75 & 1,0 \\
\hline Alecrim-pimenta & $97,50 \mathrm{~A}$ & $93,50 \mathrm{~A}$ & $85,00 \mathrm{~A}$ & $73,50 \mathrm{~A}$ & $76,00 \mathrm{~A}$ \\
\hline Capim-santo & $87,50 \mathrm{~A}$ & $59,50 \mathrm{~B}$ & $63,00 \mathrm{~B}$ & $61,50 \mathrm{~A}$ & $1,00 \mathrm{~B}$ \\
\hline $\mathrm{CV} \%$ & & & 14,5 & & \\
\hline \multicolumn{6}{|c|}{ Índice de velocidade de germinação (IVG) } \\
\hline Alecrim-pimenta & $47,37 \mathrm{~A}$ & $44,56 \mathrm{~A}$ & $41,41 \mathrm{~A}$ & $33,03 \mathrm{~A}$ & $32,76 \mathrm{~A}$ \\
\hline Capim-santo & $43,32 \mathrm{~A}$ & $28,32 \mathrm{~B}$ & $24,90 \mathrm{~B}$ & $27,14 \mathrm{~A}$ & $0,12 \mathrm{~B}$ \\
\hline $\mathrm{CV} \%$ & & & 20,4 & & \\
\hline \multicolumn{6}{|c|}{ Comprimento do hipocótilo $(\mathrm{cm})$} \\
\hline Alecrim-pimenta & $3,70 \mathrm{~A}$ & $2,44 \mathrm{~A}$ & $2,05 \mathrm{~A}$ & $1,14 \mathrm{~B}$ & $0,56 \mathrm{~A}$ \\
\hline Capim-santo & $3,43 \mathrm{~A}$ & $1,46 \mathrm{~B}$ & $2,04 \mathrm{~A}$ & $1,97 \mathrm{~A}$ & $0,00 \mathrm{~B}$ \\
\hline $\mathrm{CV} \%$ & & & 18,4 & & \\
\hline \multicolumn{6}{|c|}{ Comprimento da radícula $(\mathrm{cm})$} \\
\hline Alecrim-pimenta & $2,26 \mathrm{~A}$ & $2,77 \mathrm{~A}$ & $2,77 \mathrm{~A}$ & $2,07 \mathrm{~B}$ & $1,2 \mathrm{~A}$ \\
\hline Capim-santo & $1,76 \mathrm{~A}$ & $2,50 \mathrm{~A}$ & $2,85 \mathrm{~A}$ & $3,49 \mathrm{~A}$ & $0,0 \mathrm{~B}$ \\
\hline CV\% & & & 18,4 & & \\
\hline \multicolumn{6}{|c|}{ \% de plântulas anormais } \\
\hline Alecrim-pimenta & $4,00 \mathrm{~A}$ & $8,50 \mathrm{~A}$ & $10,00 \mathrm{~A}$ & $56,50 \mathrm{~A}$ & $76,00 \mathrm{~A}$ \\
\hline Capim-santo & $7,25 \mathrm{~A}$ & $25,50 \mathrm{~A}$ & $12,50 \mathrm{~A}$ & $13,50 \mathrm{~B}$ & $1,00 \mathrm{~B}$ \\
\hline $\mathrm{CV} \%$ & & & 49,0 & & \\
\hline
\end{tabular}

Médias seguidas por mesma letra na coluna, não diferem entre si pelo teste de Tukey a 1\% de probabilidade.

Fonte: Elaboração dos autores.

Figura 1. Germinação de aquênios de alface em função da concentração e óleo essencial de alecrim-pimenta e capimsanto.

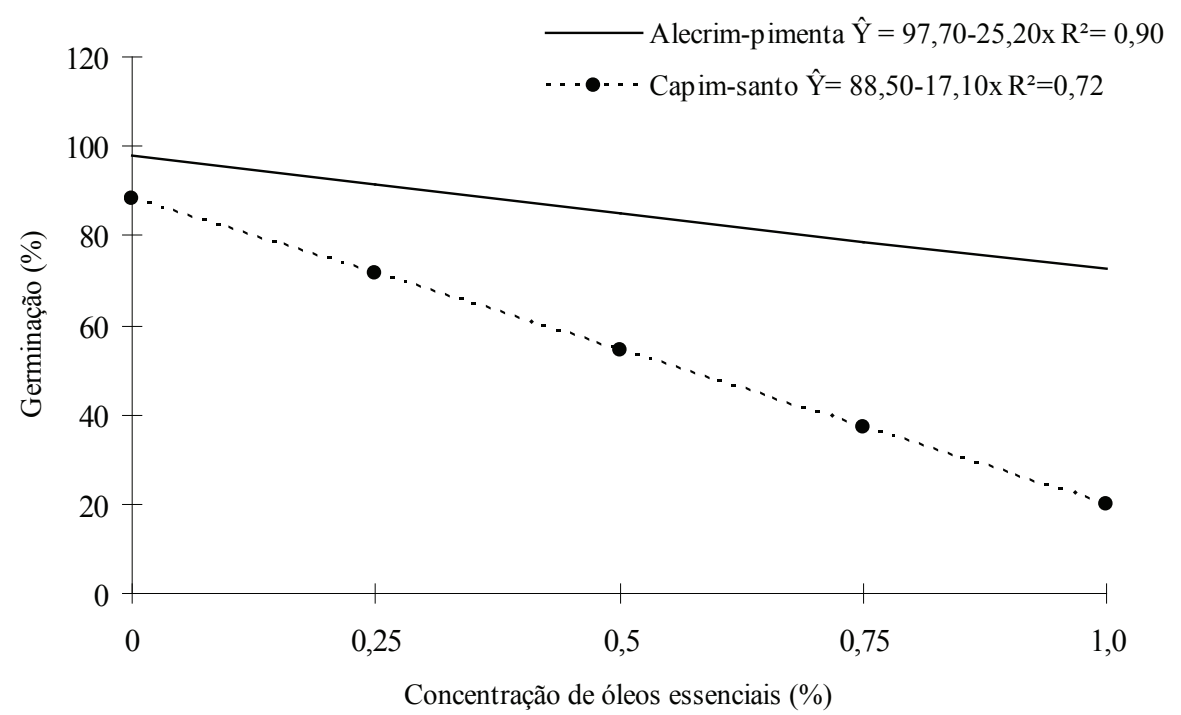

Fonte: Elaboração dos autores. 
Figura 2. Índice de velocidade de germinação (IVG) de aquênios de alface em função da concentração e óleo essencial de alecrim-pimenta e capim-santo.

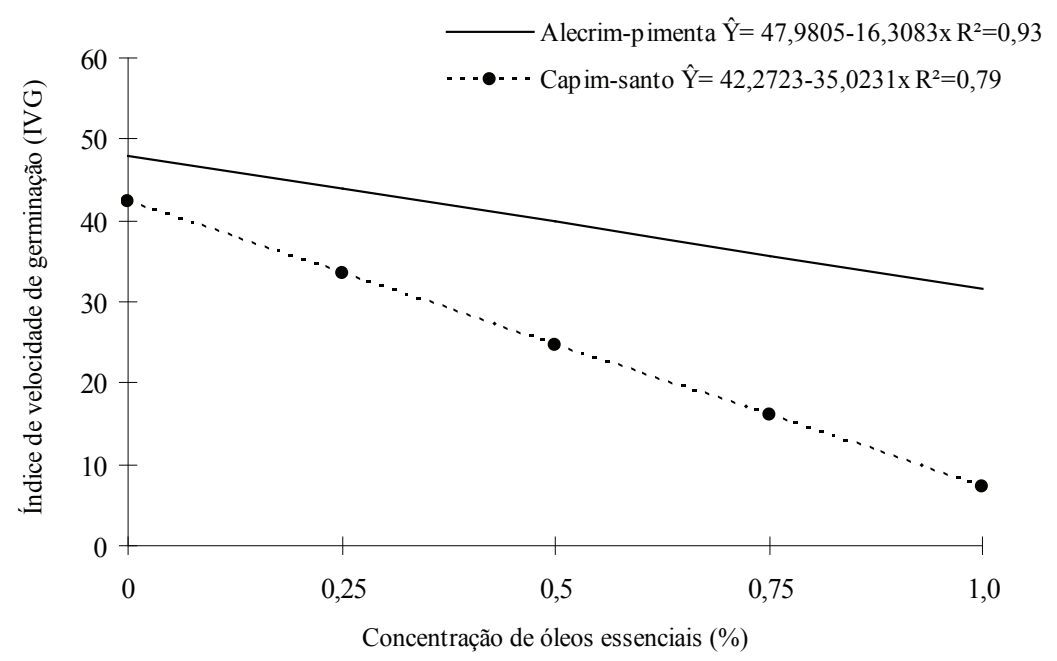

Fonte: Elaboração dos autores.

A ação dos aleloquímicos é verificada em menor proporção sobre o percentual final de germinação, sendo o mais comum o efeito negativo ou positivo no vigor e desenvolvimento das plântulas (FERREIRA; ÁQUILA, 2000). No presente estudo, ambas as situações foram observadas sendo constatados efeitos negativos sobre a germinação e a velocidade de germinação. Weir, Park e Vivanco (2004) sugerem que dois mecanismos principais podem estar envolvidos, a paralisação da respiração mitocondrial e a perturbação de enzimas do ciclo de Krebs, já que durante a germinação das sementes, há um rápido aumento na atividade glicolítica ligado a um aumento da taxa de respiração (PODESTA; PLAXON, 1994). Esta atividade glicolítica é necessária para mobilizar os carboidratos armazenados, fornecer a semente poder redutor, ATP e produtos de carbono necessário para a biossíntese das raízes e parte aérea das plântulas emergentes, se o processo de respiração é comprometido, consequentemente a germinação é afetada. Outro mecanismo envolvido deve-se a perturbação da atividade de enzimas metabólicas que estão envolvidas na glicólise e via pentoses fosfato oxidativo (OPPP) (MUSCOLO;
PANUCCIO; SIDARI, 2001). Esse modo de ação foi verificado para sementes de Pinus laricio que tiveram menor germinação em decorrência a uma menor atividade de enzimas envolvidas na glicólise e via pentoses fosfato ocasionada por compostos fenólicos (MUSCOLO; PANUCCIO; SIDARI, 2001), que são comuns em extratos de plantas medicinais.

Em muitas plantas medicinais é comum a presença de terpenoides, sendo os monoterpenoides e sesquiterpenoides responsáveis por grande parte das atividades biológicas dos óleos essenciais (MORAES, 2009). Para Alves et al. (2004) é possível que a presença do monoterpeno timol, composto encontrado em maior quantidade no óleo de alecrim-pimenta (Lippia sidoides Cham.) seja o principal componente responsável pelo efeito fitotóxico na germinação de aquênios de alface. Um estudo realizado por Kaur et al. (2010) revelou que dos $99 \%$ de constituintes presentes no óleo de artemísia (Artemisia scoparia) 55,20\% são monoterpenoides e 3,6\% sesquiterpenoides sendo esses compostos relacionados ao efeito inibitório da germinação em seis espécies de plantas daninhas. 
No presente estudo, a concentração dos óleos foi um fator importante para condicionar um efeito negativo na germinação. Demonstrando que não basta somente a presença do composto, mas este deve estar em quantidade ideal para que possa ocasionar danos fisiológicos ou bioquímicos (WEIR; PARK; VIVANCO, 2004). Também nos trabalhos de Alves et al. (2004) e Kaur et al. (2010) a germinação de alface e plantas daninhas foi comprometida de acordo com o aumento da concentração de óleo utilizada.

O comprimento da radícula de alface somente foi influenciado pelo tipo de óleo a partir da concentração de $0,75 \%$ para o alecrim-pimenta, que limitou o crescimento radicular quando comparado ao óleo obtido do capim-santo. $\mathrm{Na}$ concentração de $1 \%$ houve diferença estatística, entretanto, esse resultado deve-se em função da baixa porcentagem de germinação(1\%)(Tabela 1) nos aquênios de alface que receberam esse tratamento, onde praticamente não houve desenvolvimento da plântula e protrusão da radícula (Tabela 1). O crescimento do hipocótilo de alface foi limitado em $0,25 \%$ de capim-santo e $0,75 \%$ de alecrim-pimenta. Não sendo observadas diferenças estatísticas para os dois tipos de óleos nas demais concentrações (Tabela 1).

O aumento das concentrações de óleo essencial de alecrim-pimenta e capim-santo em contato com os aquênios de alface resultaram em decréscimo linear no comprimento do hipocótilo das plântulas (Figura 3). Para o crescimento da radícula o melhor modelo ajustado foi o quadrático, em que após as concentrações de $0,45 \%$ para o capim-santo e $0,35 \%$ para o alecrim-pimenta o efeito foi negativo sobre o desenvolvimento dessa característica (Figura 4).

Figura 3. Comprimento do hipocótilo de plântulas de alface $(\mathrm{cm})$ em função da concentração e óleo essencial de alecrim-pimenta e capim-santo.

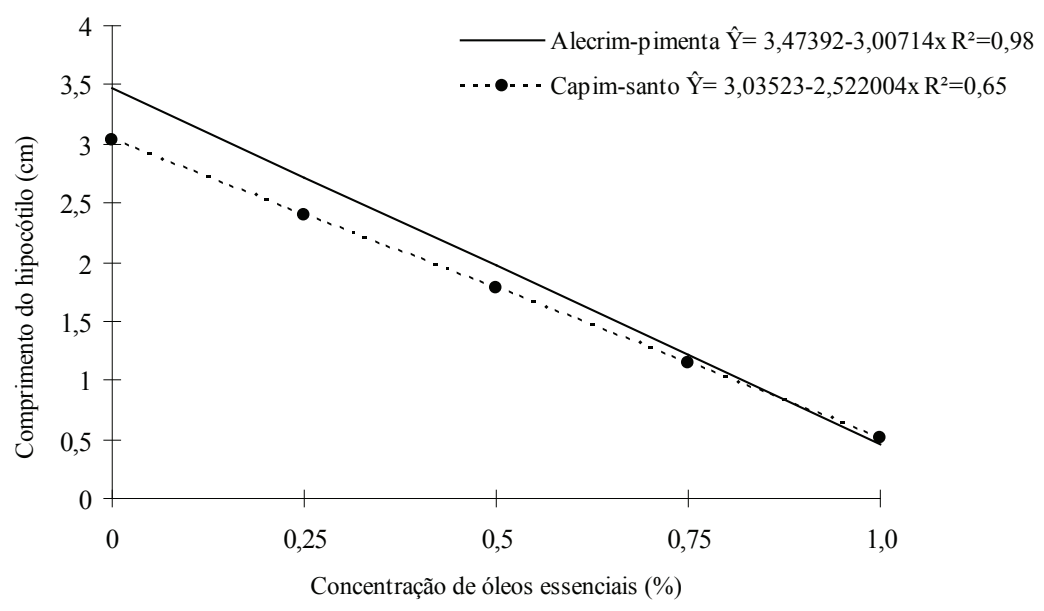

Fonte: Elaboração dos autores.

No presente estudo verificou-se que as em atividades bioquímicas e fisiológicas. concentrações tiveram ação diferenciada no Posteriormente, o efeito veio a serfitotóxicoàs raízes. crescimento da radícula e do hipocótilo. Na A ação do aleloquímicos pode variar conforme o radícula em primeiro instante ou as concentrações órgão da planta onde atuam, sendo capazes de causar estimularam o crescimento ou não interferiram inibições em determinadas regiões e incrementos 
em outras (AQUILA; UNGARETTI, J. A. C.; MICHELIN, 1999), sendo também possível ocorrer hormese nesses tecidos, segundo Belz, Cedergreen e Duke (2011) embora algumas substâncias, tóxicas em altas doses, podem ser benéficas e estimulatórias em baixas concentrações. Nos trabalhos realizados por (PINA et al., 2009; PARVEZ et al., 2003), a fitotoxidade variou conforme o órgão das plântulas sendo em alguns casos fortemente influenciada pela concentração do composto.
A massa seca do hipocótilo de alface reduziu linearmente em função do aumento das concentrações de óleos essenciais de capim-santo e alecrim-pimenta (Figura 5). Não foi observado efeito significativo das concentrações do óleo de alecrim-pimenta para massa seca da radícula (Figura 6). Em relação ao capim-santo, com o aumento da concentração do óleo essencial em contato com os aquênios de alface, a massa seca desse órgão diminuiu linearmente (Figura 6).

Figura 4. Comprimento da radícula de plântulas de alface $(\mathrm{cm})$ em função da concentração e óleo essencial de alecrim-pimenta e capim-santo.

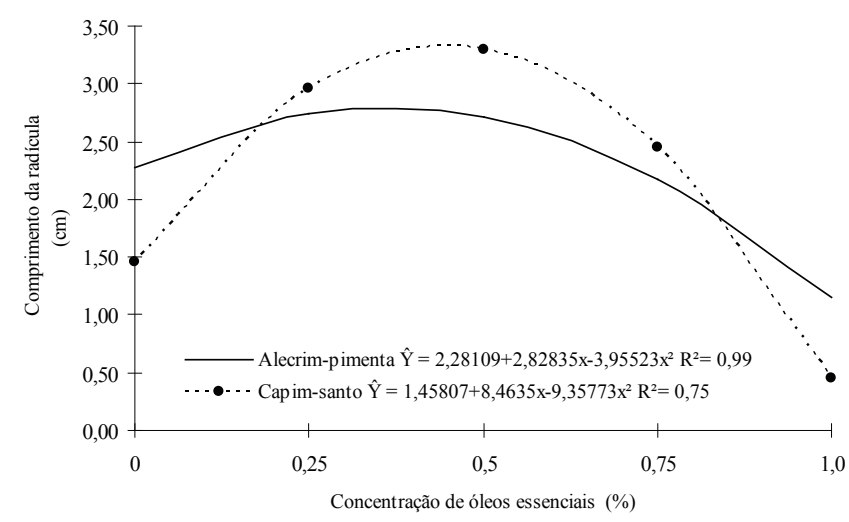

Fonte: Elaboração dos autores.

Figura 5. Massa seca do hipocótilo de plântulas de alface (g) em função da concentração e óleo essencial de alecrimpimenta e capim-santo.

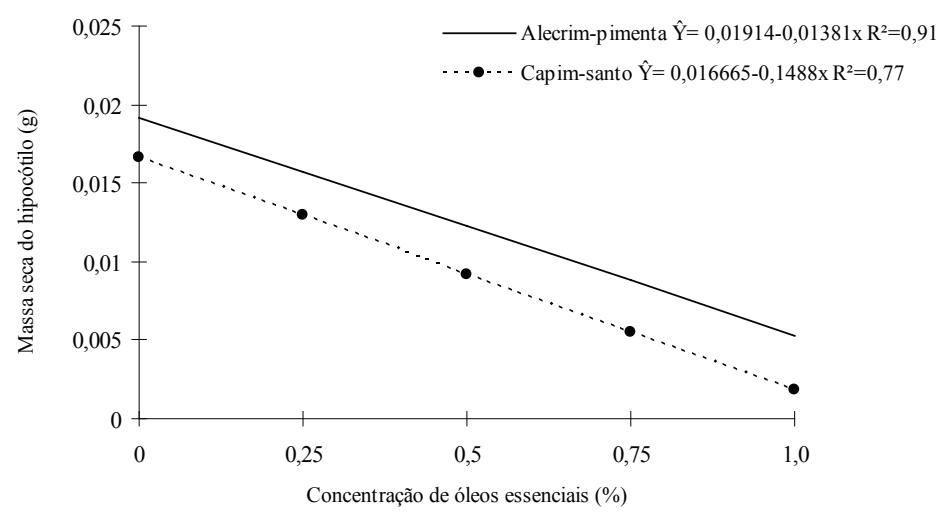

Fonte: Elaboração dos autores. 
Figura 6. Massa seca da radícula de plântulas de alface (g) em função da concentração e óleo essencial de alecrimpimenta e capim-santo.

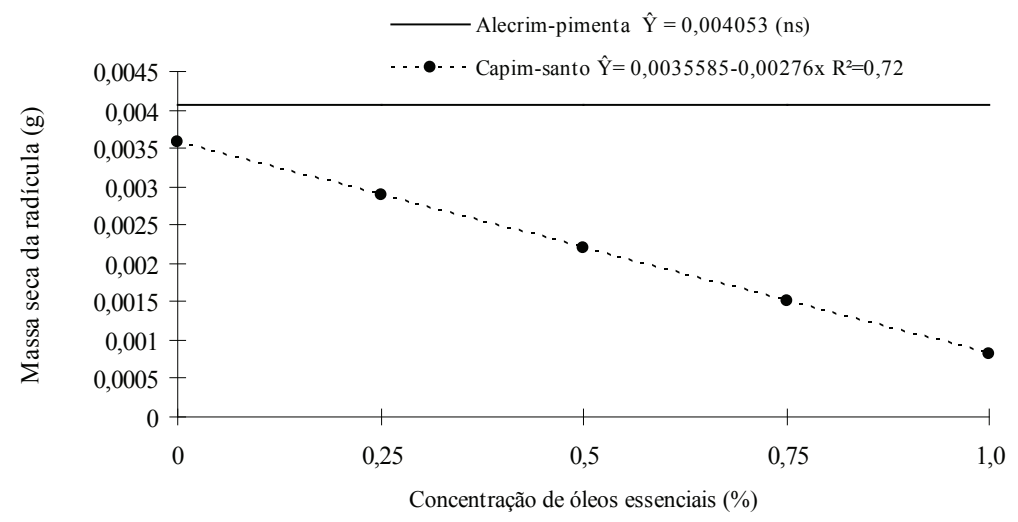

Fonte: Elaboração dos autores.

O extrato aquoso da folha de Dittrichia viscosa sobre plântulas de alface reduziu significativamente o comprimento e a massa seca da raiz não sendo observado efeito para o comprimento e massa seca da parte área (LEVIZOU et al., 2002). O limoeno, gerarniol e o neral foram as substâncias em maior quantidade identificadas no óleo essencial de capimsanto (TZORTZAKIS; ECONOMAKIS, 2007) e podem estar relacionados à inibição das raízes de alface nesse ensaio. Os aleloquímicos possuem diversos mecanismos que podem comprometer o crescimento e o ganho em matéria seca das plântulas, atuando na atividade de fitormônios que agem na divisão e ou do alongamento celular, na síntese de ácido nucléico e proteínas, na quantidade de oxigênio que chega ao embrião, na permeabilidade das membranas e inibição da fotossíntese (TAYLOR; GROTEWOLD, 2005; WEIR; PARK; VIVANCO, 2004).
Aquênios de alface expostos ao óleo de alecrimpimenta nas concentrações de $0,75 \%$ e $1,0 \%$ durante sua germinação tiveram porcentagens elevadas de plântulas anormais (56,5\% e 75,0\%), quando comparado com o capim-santo (Tabela 1). A curva assumiu modelo quadrático sendo que após $0,05 \%$ quanto maior a concentração do óleo de alecrim-pimenta em contato com as sementes de alface maior a proporção de plântulas anormais formadas (Figura 7). Para o capim-santo não houve diferença estatística entre as concentrações, para percentagem de plantas anormais (Figura 7). Embora a porcentagem de germinação dos aquênios de alface submetidos ao óleo de alecrim-pimenta foi elevada nas mesmas concentrações de $0,75 \%$ e 1,0\% houve a produção de plântulas anormais que dificultaria a sobrevivência no campo. Outras características visuais analisadas não apresentaram diferenças em função dos óleos testados e da sua concentração. 
Figura 7. Porcentagem de plântulas anormais de alface (\%) em função da concentração e óleo essencial de alecrimpimenta e capim-santo.

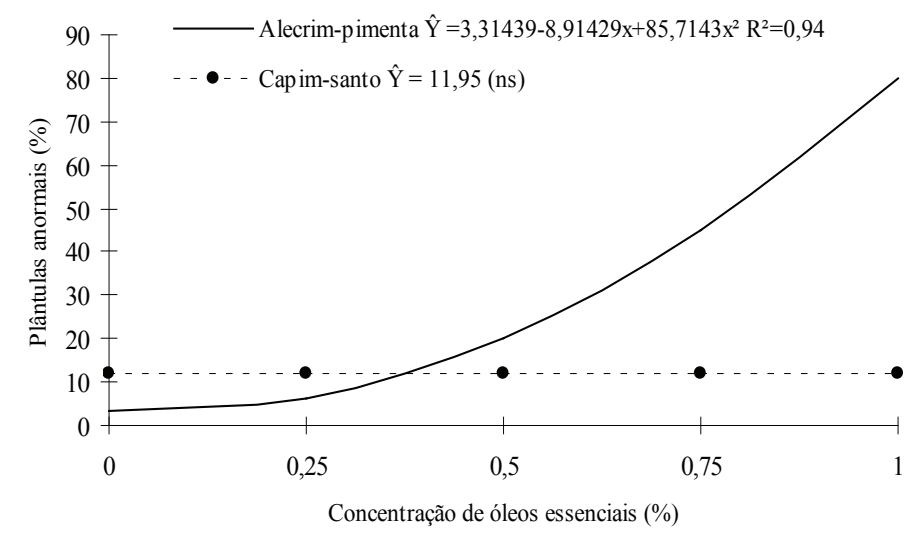

Fonte: Elaboração dos autores.

Levizou et al. (2002) avaliando o efeito de extratos obtidos das folhas de Dittrichia viscosa verificaram alta incidência de raízes laterais e movimento gravitrópico alterado. Também Pina et al. (2009) observaram plântulas anormais, necrose nos tecidos e desenvolvimento de raízes laterais de plântulas de rabanete e gergelim quando tratadas com extratos da folha de cagaiteira (Eugenica dysenterica). Possivelmente, os níveis hormonais podem ter sido influenciados com a presença dos aleloquímicos. Jacobs e Rubery (1988) ressaltam que alguns inibidores atuam alterando os níveis normais de auxinas, resultando em plântulas anormais, crescimento ageotrópico e raízes laterais, contudo, Levizou et. al. (2002) ressaltam que os efeitos também podem ser a nível celular, como a baixa frequência de divisão na zona meristemática apical da raiz, resultando em crescimento suprimido das raízes e coifa, e na orientação dos tecidos em desenvolvimento. É possível que essas hipóteses se apliquem no presente trabalho, entretanto, seriam necessários estudos anatômicos, fisiológicos e bioquímicos do real envolvimento dos óleos de alecrim-pimenta e o capim-santo sobre plantas bioindicadoras.

\section{Conclusões}

O óleo de capim-santo reduziu com maior intensidade a germinação de aquênios de alface, quando comparado com o óleo de alecrim-pimenta, com efeitos proporcionais às concentrações utilizadas.

O vigor das plântulas de alface foi comprometido pelos óleos de alecrim-pimenta e capim-santo.

Em ambos os óleos, concentrações acima de $0,25 \%$ reduziram o comprimento e a massa do hipocótilo e acima de $0,75 \%$ reduziram o comprimento da radícula.

A massa seca da radícula foi reduzida apenas pelo óleo de capim-santo, a partir de $0,25 \%$.

O alecrim-pimenta proporcionou elevada porcentagem de plântulas anormais.

\section{Agradecimentos}

Paulo N. S. Lopes agradece ao CNPq pela concessão da bolsa de desenvolvimento tecnológico e extensão inovadora (número do processo 313116/2009-1). 


\section{Referências}

ALVES, M. C. S.; FILHO, S. M.; INNECCO, R.; TORRES, S. B. Alelopatia de extratos voláteis na germinação de sementes e no comprimento da raiz de alface. Pesquisa Agropecuária Brasileira, Brasília, v. 39, n. 11, p. 1083-1086, 2004.

AQUILA, M. E. A.; UNGARETTI, J. A. C.; MICHELIN, A. Preliminary observation on allelopathic activity in Achyrocline satureoides (Lam) DC. Acta Horticulturae, Leuven, v. 502, p. 383-388, 1999. Disponível em: $<$ http:// www.actahort.org/books/502/502_63.htm>. Acesso em: 10 abr. 2011.

BANZATTO, D. A.; KRONKA, S. N. Experimentação agrícola. 4. ed. Jaboticabal: Funep, 2006. 237 p.

BELZ, R. G.; CEDERGREEN, N.; DUKE, S. O. Herbicide hormesis - can it be useful in crop production? Weed Research, 2011. Disponível em: <http://onlinelibrary. wiley.com/doi/10.1111/j.1365-3180.2011.00862.x/pdf>. Acesso em: 29 maio 2011.

BRASIL. Ministério da Agricultura Pecuária e Abastecimento. Regras para análise de sementes. Brasília, DF: SNDA/DNDV/CLV, 2009. 395 p.

DAIZY, R. B.; SETIA, H.; SINGH, H. P.; KOHLI, R. K. Phytotoxicity of lemon-scented eucalypt oil and its potential use as a bioherbicide. Crop Protection, v. 23, p. 1209-1214, 2004. Disponível em: $<$ http://www.sciencedirect.com/science/article/pii/ S026121940400136X $>$. Acesso em: 15 maio 2011.

DE FEO, V.; SIMONE, F.; SENATORE, F. Potential allelochemicals from the essential oil of Ruta graveolens. Phytochemistry, Oxford, v. 61, n. 5, p. 573-578, 2002.

FAROOQ, M.; JABRAN, K.; ZAHID, A. C.; WAHID, A.; SIDDIQUE, K. H. M. The role of allelopathy in agricultural pest management. Pest Management Science, Weinheim, v. 67, n. 5, p. 493-506, 2011.

FERREIRA, A. G.; ÁQUILA, M. E. A. Alelopatia: uma área emergente da ecofisiologia. Revista Brasileira de Fisiologia Vegetal, Brasília, v. 12, p. 175-204, 2000. Especial.

JACOBS, M.; RUBERY, P. H. Naturally occurring auxin transport regulators. Science, Washington, v. 241, n. 15, p. 346-349, 1988.

KAUR, S.; SINGH, H. P.; MITTAL, S.; BATISH, D. R.; KOHLI, R. K. Phytotoxic effects of volatile oil from Artemisia scoparia against weeds and its possible use as a bioherbicide. Industrial Crops and Products, Amsterdam, v. 32, n. 1, p. 54-61, 2010.
LEVIZOU, E.; KARAGEORGOU, P.; PSARAS, G. K.; MANETAS, Y. Inhibitory effects of water soluble leaf leachates from Dittrichia viscosa on lettuce root growth, statocyte development and graviperception. Flora, v. 197, n. 2, p. 152-157, 2002.

MAGIERO, E. C.; ASSMANN, J. M.; MARCHESE, J. A.; CAPELIN, D.; PALADINI, M. V.; TREZZI, M. M. Efeito alelopático de Artemisia annua L. na germinação e desenvolvimento inicial de plântulas de alface (Lactuca sativa L.) e leiteiro (Euphorbia heterophylla L.). Revista Brasileira de Plantas Medicinais, Botucatu, v. 11, n. 3, p. 317-324, 2009.

MAGUIRE, J. D. Speed of germination in selection and evaluation for seedling emergence and vigour. Crop Science, Madison, v. 2, n. 2, p. 176-177, 1962.

MARTINS, E. R.; CASTRO, D. M.; CASTELLANI, D. C.; EVANGELISTA, D. J. Plantas medicinais. UFV, Viçosa, 2002. 220 p.

MORAES, L. A. S. Óleos essenciais no controle fitossanitário. In: BETTIOL, W.; MORANDI, M. A. B. (Ed.). Biocontrole de doenças de plantas: uso e perspectivas. Jaguariúna: EMBRAPA Meio Ambiente, 2009. p. 139-152.

MUSCOLO, A.; PANUCCIO, M. R.; SIDARI, M. The effect of phenols on respiratory enzymes in seed germination respiratory enzyme activities during germination of Pinus laricio seeds treated with phenols extracted from different forest soils. Plant Growth Regulation, Dordrescht, v. 35, n. 1, p. 31-35, 2001.

PARVEZ, S. S.; PARVEZ, M. M.; NISHIHARA, E.; GEMMA, H.; FUJII, H. Tamarindus indica L. leaf is a source of allelopathic substance. Plant Growth Regulation, Dordrescht, v. 40, n. 2, p. 107-115, 2003.

PINA, G. O.; BORGHETTI, F.; SILVEIRA, C. E. S.; PEREIRA, L. A. R. Effects of Eugenia dysenterica leaf extracts on the growth of sesame and radish. Allelopathy Journal, v. 23, n. 2, n. 2, p. 313-322, 2009.

PODESTA, E. E.; PLAXTON, W. C. Regulation of cytosolic carbon metabolism in germinating Ricinus communis cotyledons. Developmental profiles for the activity, concentration, and molecular structure of the pyrophosphateandATP-dependentphosphofructokinases, phosphoenolpyruvate carboxylase and pyruvate kinase. Planta, v. 194, n. 3, p. 374-380, 1994.

ROSADO, L. D. S.; RODRIGUES, H. C. A.; PINTO, J. E. B. P.; CUSTÓDIO, T. N.; PINTO, L. B. B.; BERTOLUCCI, S. K. V. Alelopatia do extrato aquoso e do óleo essencial de folhas do manjericão "Maria Bonita" 
na germinação de alface, tomate e melissa. Revista Brasileira de Plantas Medicinais, Botucatu, v. 11, n. 4, p. 422-428, 2009.

SALAMCI, E.; KORDALI, S.; KOTAN, R.; CAKIR, A. KAYA, Y. Chemical compositions, antimicrobial and herbicidal effects of essential oils isolated from Turkish Tanacetum aucheranum and Tanacetum chiliophyllum var. chiliophyllum. Biochemical Systematics and Ecology, Surrey, v. 35, n. 9, p. 569-581, 2007.

SODAEIZADEH, H.; RAFIEIOLHOSSAIN, M.; VANDAMM, P. Herbicidal activity of a medicinal plant, Peganum harmala L., and decomposition dynamics of its phytotoxins in the soil. Industrial Crops and Products, Amsterdam, v. 31, n. 2, p. 385-394, 2010.
TAYLOR, L. P.; GROTEWOLD, E. Flavonoids as developmental regulators. Current Opinion in Plant Biology, Saint Louis, v. 8, n. 3, p. 317-323, 2005.

TZORTZAKIS, N. G.; ECONOMAKIS, C. D. Antifungal activity of lemongrass (Cympopogon citratus L.) essential oil against key postharvest pathogens. Innovative Food Science and Emerging Technologies, Heverlee, v. 8, n. 2, p. 253-258, 2007.

WEIR, T. L.; PARK, S. W.; VIVANCO, J. M. Biochemical and physiological mechanisms mediated by allelochemicals. Current Opinion in Plant Biology, Saint Louis, v. 7, n. 4, p. 472-479, 2004. 
